\title{
Scope and Methodology of Twin Studies
}

\section{SCOPE AND METHODOLOGY OF TWIN STUDIES}

\section{GORDON ALLEN}

National Institute of Mental Health, U.S. Public Health Service, Bethesda, Maryland, USA

Twin research has not become obsolete as its critics of twenty years ago perhaps expected it would. Old, familiar research designs are finding new applications, and new research designs are appearing. Of greatest interest are the epidemiological studies that depend on the assembly or the aging of large numbers of twins in twin registries. As an outgrowth partly of the twin registries, partly of conceptual and mathematical progress, new methods have emerged for diagnosis of twin types and for analysis of twin data. One line of development started with the questionnaire method of zygosity diagnosis and has given rise most recently to zygosity diagnosis by principal component analysis. Another line started with probability calculations and has led to the use of generalized distance and noncentral chi-square. The appropriateness of these methods in different contexts needs to be critically reviewed.

Among numerous research attacks on the phenomenon of twinning, some have potential impact on the "experimental" uses of twins. A good example is the analysis of the peculiarities of the environment of twins, which is of course very important in psychological twin research.

Gordon Allen, M.D., NIMH, 10/3 D 39 , Bethesda, Maryland 200 14, USA

\section{APPLICATIONS AND \\ PERSPECTIVES OF TWIN STUDIES IN POPULATION GENETICS}

\section{G. BRENCI}

The Gregor Mendel Institute of Medical Genetics and Twin Research, Rome, Italy

The study of populations and of twin samples as a method of human genetic research today still has, for the majority of human geneticists, the same meaning that it had in 1876 when Galton published his History of Twins as a Criterium of the Relative Powers of Nature and Nurture.

For a more complete evaluation of the possibility of research originating from an experimental twin plane, a quick survey is made of the present development of the methods connected with the problem of the relationship between heredity and environment, to then pass to examine the probability offered by twin data to solve problems of population genetics, such as the appraisal of genotypic and genic frequencies, the establishment of transmission models, the calculation of penetrance, linkage estimate, and mutation rate.

Finally, and as a suggestive perspective, it is stressed how twins may be used for the analysis of genetic distance.

G. Brenci, Istituto Mendel, Piazza Galeno 5, oor6r Roma, Italy

\section{DOWN'S SYNDROME IN TWINS: LACK OF EVIDENCE FOR INDEPENDENCE OF NONDISJUNGTION AND DIZYGOTIC TWINNING}

\section{LARRY L. MAI}

Laboratory of Physical Anthropology, University of California, Los Angeles, California, USA

An hypothesis is examined which considers the assumption of twin methodology that only two modes of twinning exist. The null hypothesis that $\mathrm{DZ}$ twinning and concordance for Down's syndrome are independent events is tested after removal of effects such as covariance due to maternal age. The null hypothesis is rejected $(P<0.000002)$.

Possible explanations of the result considered are (a) that some of the cases are $\mathrm{MZ}$ 